\title{
Performance of the Cox-maze IV procedure is associated with improved long-term survival in patients with atrial fibrillation undergoing cardiac surgery
}

\author{
Farah N. Musharbash, Matthew R. Schill, MD, Laurie A. Sinn, RN, BSN, Richard B. Schuessler, PhD, \\ Hersh S. Maniar, MD, Marc R. Moon, MD, Spencer J. Melby, MD, and Ralph J. Damiano, Jr, MD
}

\section{ABSTRACT}

Objective: Atrial fibrillation (AF) is associated with an increased mortality risk. The Cox-maze IV procedure (CM4) performed concomitantly with other cardiac procedures has been shown to be effective for restoring sinus rhythm. However, few data have been published on the late survival of patients undergoing a concomitant CM4.

Methods: Patients undergoing cardiac surgery were retrospectively reviewed from 2001 to $2016(\mathrm{n}=10,859)$. Patients were stratified into 3 groups: patients with a history of AF receiving a concomitant CM4 (CM4; $n=438)$, patients with a history of AF unaddressed during surgery (Untreated AF; $n=1510$ ), and patients without AF history (No AF; $n=8911$ ). Propensity score matching was conducted between the CM4 and Untreated AF groups, and between the CM4 and No AF groups.

Results: Thirty-day mortality was similar between the matched groups. Kaplan-Meier analysis showed greater survival for CM4 compared to Untreated AF $(P=.004)$. Ten-year survival was $62 \%$ for CM4 and $42 \%$ for Untreated AF. Adjusted hazard ratio was 0.47 (95\% confidence interval, 0.26-0.86, $P=.014)$. No difference in survival was found between CM4 and No AF groups with the Kaplan-Meier analysis $(P=.847)$. Ten-year survival was $63 \%$ for CM4 and $55 \%$ for No AF. Adjusted hazard ratio was 1.03 (95\% confidence interval, $0.51-2.11, P=.929)$.

Conclusions: For selected patients with a history of AF undergoing cardiac surgery, concomitant CM4 did not add significantly to postoperative morbidity or mortality and was associated with improved late survival compared with patients with untreated AF and a similar survival to patients without a history of AF. (J Thorac Cardiovasc Surg 2018;155:159-70)

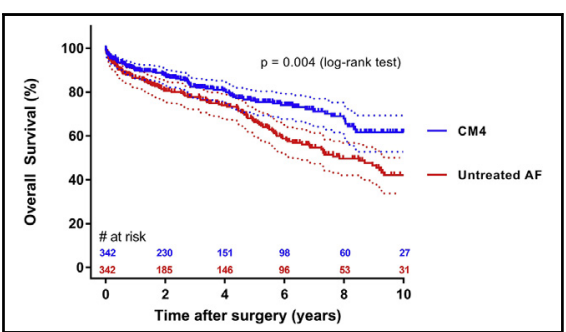

Survival of concomitant Cox-maze versus no ablation for atrial fibrillation during surgery.

\section{Central Message}

In patients with a history of atrial fibrillation undergoing cardiac surgery, a concomitant Cox-maze IV procedure was associated with improved long-term survival.

\section{Perspective}

The effectiveness of surgical ablation for the treatment of atrial fibrillation has been well established. However, most patients with atrial fibrillation undergoing heart surgery do not receive concomitant ablation. Our findings show that the addition of a Cox-maze IV procedure does not add significantly to postoperative morbidity or mortality and is associated with improved long-term survival.

See Editorial Commentary page 171

See Editorial page 157.

\footnotetext{
From the Division of Cardiothoracic Surgery, Washington University School of Medicine, Barnes-Jewish Hospital, St Louis, Mo.

F. N. Musharbash is supported by the Washington University Summer Research Program Dean's Fellowship. M. R. Schill is supported by T32-HL007776. R. J. Damiano, Jr, is supported by R01-HL032257.

Read at the 97th Annual Meeting of The American Association for Thoracic Surgery, Boston, Massachusetts, April 29-May 3, 2017.

Received for publication April 23, 2017; revisions received Aug 5, 2017; accepted for publication Sept 6, 2017; available ahead of print Oct 19, 2017.

Address for reprints: Ralph J. Damiano, Jr, MD, Washington University School of Medicine/Barnes-Jewish Hospital, Suite 3108 Queeny Tower, 1 Barnes-Jewish Hospital Plaza, Saint Louis, MO 63110 (E-mail: damianor@wustl.edu). $0022-5223 / \$ 36.00$

Copyright (c) 2017 by The American Association for Thoracic Surgery https://doi.org/10.1016/j.jtcvs.2017.09.095
}

Atrial fibrillation (AF) is the most common cardiac arrhythmia and is associated with an adverse prognosis. Studies have shown that patients with AF are at an increased risk of stroke, heart failure, and death. ${ }^{1,2}$ This also was the case for patients undergoing cardiac surgery with a history

$\square$ Scanning this QR code will take
you to a supplemental video. To
view the AATS 2016 Webcast,
see the URL next to the webcast
thumbnail.




$$
\begin{aligned}
& \text { Abbreviations and Acronyms } \\
& \begin{aligned}
\text { AAD } & =\text { antiarrhythmic drugs } \\
\text { AF } & =\text { atrial fibrillation } \\
\text { CABG } & =\text { coronary artery bypass grafting } \\
\text { CI } & =\text { confidence interval } \\
\text { CM4 } & =\text { Cox-maze IV procedure } \\
\text { NYHA } & =\text { New York Heart Association } \\
\text { STS } & =\text { Society of Thoracic Surgeons }
\end{aligned}
\end{aligned}
$$

of $\mathrm{AF}$, who have a worse associated morbidity with an increased incidence of stroke and heart failure compared with patients without $\mathrm{AF}^{3,4}$ These patients had significantly worse late survival as well. ${ }^{5-7}$

Several studies have demonstrated survival benefits for patients with a history of AF undergoing concomitant surgical ablation. ${ }^{8-10}$ A similar benefit has been observed in patients with only paroxysmal preoperative $\mathrm{AF}{ }^{11}$

The Cox-maze procedure has been shown to be an effective surgical treatment of AF. Originally introduced by Dr. James Cox in 1987 as a "cut-and-sew" operation, it underwent several revisions on the basis of extensive clinical experience and investigations in animals at our institution. ${ }^{12}$ The ablation-assisted Cox-maze IV procedure (CM4), introduced 15 years ago, has dramatically shortened and simplified the operation and has decreased morbidity and mortality. The CM4 is currently the gold standard surgical treatment for $\mathrm{AF}$, with a $93 \%$ freedom from $\mathrm{AF}$ and $85 \%$ freedom from $\mathrm{AF}$ and antiarrhythmic drugs (AAD) at 1 year, and a $78 \%$ freedom from $\mathrm{AF}$ and $66 \%$ freedom from $\mathrm{AF}$ and $\mathrm{AAD}$ at 5 years. ${ }^{13} \mathrm{CM} 4$ has been shown not to add to the morbidity or mortality of mitral valve repair, aortic valve replacement, or coronary artery bypass grafting (CABG). ${ }^{10,14,15}$

The purpose of this study was to compare the late survival of patients with AF undergoing cardiac surgery who received a concomitant CM4 with 2 other groups: patients with a history of AF undergoing cardiac surgery without receiving any concomitant surgical $\mathrm{AF}$ ablation and patients undergoing cardiac surgery without a history of AF.

\section{METHODS}

The study was approved by the Institutional Review Board of the Washington University School of Medicine (ID\#: 201610023, approved on October 12, 2016), with a waiver of patient consent. Demographic and perioperative clinical data, including preoperative AF history, were collected from our institutional Society of Thoracic Surgeons (STS) database and our own institutional AF database. Mortality data were obtained by query of the Social Security Death Index and our own electronic medical record database.

\section{Study Population}

Patients undergoing cardiac surgery at our institution were retrospectively reviewed from January 2001 to March 2016 (Figure 1). Patients undergoing heart transplant, transcatheter aortic valve implantation, ventricular assist devices, trauma, or stand-alone surgical $\mathrm{AF}$ ablation were excluded. In addition, patients receiving concomitant ablation procedures other than the CM4 were excluded. Patients were stratified into 3 groups: patients with a history of AF receiving a concomitant CM4 (CM4; $\mathrm{n}=438$ ); those with a history of AF not addressed during the surgery (Untreated $\mathrm{AF} ; \mathrm{n}=1510$ ); and patients without a history of AF (No AF; $\mathrm{n}=8911)$.

CM4 patients underwent mitral valve surgery $(n=279,55 \%)$, CABG $(\mathrm{n}=119,33 \%)$, aortic valve surgery $(\mathrm{n}=94,22 \%)$, and tricuspid valve surgery $(n=49,11 \%)$. The operative details of the CM4 lesion set has been described previously by our group. ${ }^{16-19}$ All of the patients in the CM4 group included in our study received a biatrial lesion set. Our standard postoperative protocol for patients receiving a CM4 includes discharging patients on class I or III AADs for rhythm control and an oral anticoagulation drug for at least 2 months, unless contraindicated. The AADs were discontinued after 2 months if the patient was in a normal sinus rhythm; anticoagulation was discontinued at 3 months if prolonged monitoring showed no $\mathrm{AF}$ and an echocardiogram showed no atrial stasis and an excluded left atrial appendage. Evaluation of freedom from atrial tachyarrhythmias and AADs was performed at 1, 2, 3 , 4, and 5 years by electrocardiogram or prolonged monitoring by either 24-hour Holter monitoring, pacemaker interrogation, or interrogation of implantable loop recorders, as recommended by the consensus guidelines. ${ }^{20}$

Twenty-three preoperative variables were compared between the original groups (Table 1) and were chosen based on their clinical significance, after a preliminary analysis of more than 100 variables from our STS database. Both the EuroSCORE II and the Ambler score were calculated to provide an estimate of the preoperative risk profile of the different patient groups.

\section{Statistical Analysis}

Continuous variables were expressed as mean \pm standard deviation or as median with interquartile range. Categorical variables were expressed as frequencies and percentages with outcomes compared with the $\chi^{2}$ or the Fisher exact test. Continuous outcomes were compared with the $t$ test for means of normally distributed continuous variables and the Mann-Whitney $U$ nonparametric test for skewed distributions. All data analyses were performed with SPSS 23.0 (IBM Corp, Armonk, NY) or $\mathrm{R}$ version 3.1.3 (The R Foundation for Statistical Computing, Vienna, Austria) statistical software.

To improve covariate balance and account for baseline and procedure-related differences, propensity score matching was conducted between our CM4 and Untreated AF groups, as well as between the CM4 and No AF groups. The SPSS plugin of the R MatchIt package was used to estimate the propensity score using a logistic model with nearest neighbor algorithm and a 1:1 match ratio. We imposed a caliper of 0.1 standard deviation of the logit of the propensity score. The covariates used to create the propensity model were chosen based on the results of the comparison between the original groups as well as their clinical relevance. The 22 variables selected as covariates for the matching were age, sex, New York Heart Association (NYHA) class status, ejection fraction, diabetes, dyslipidemia, last creatinine, renal failure, dialysis, hypertension, previous cerebrovascular incident, previous myocardial infarction, chronic lung disease, peripheral vascular disease, previous infective endocarditis, coronary artery disease, elective status, previous cardiac surgery, and current surgery being performed including CABG, aortic valve, mitral valve, and tricuspid valve. After matching, the covariate balance was improved for all factors (Tables 2 and 3), and this was confirmed by calculating the standardized mean difference, as well as by graphical means using the density distribution of the propensity score. The matched samples remaining included 684 patients (342 pairs) for the CM4 versus Untreated AF groups, and 804 patients 


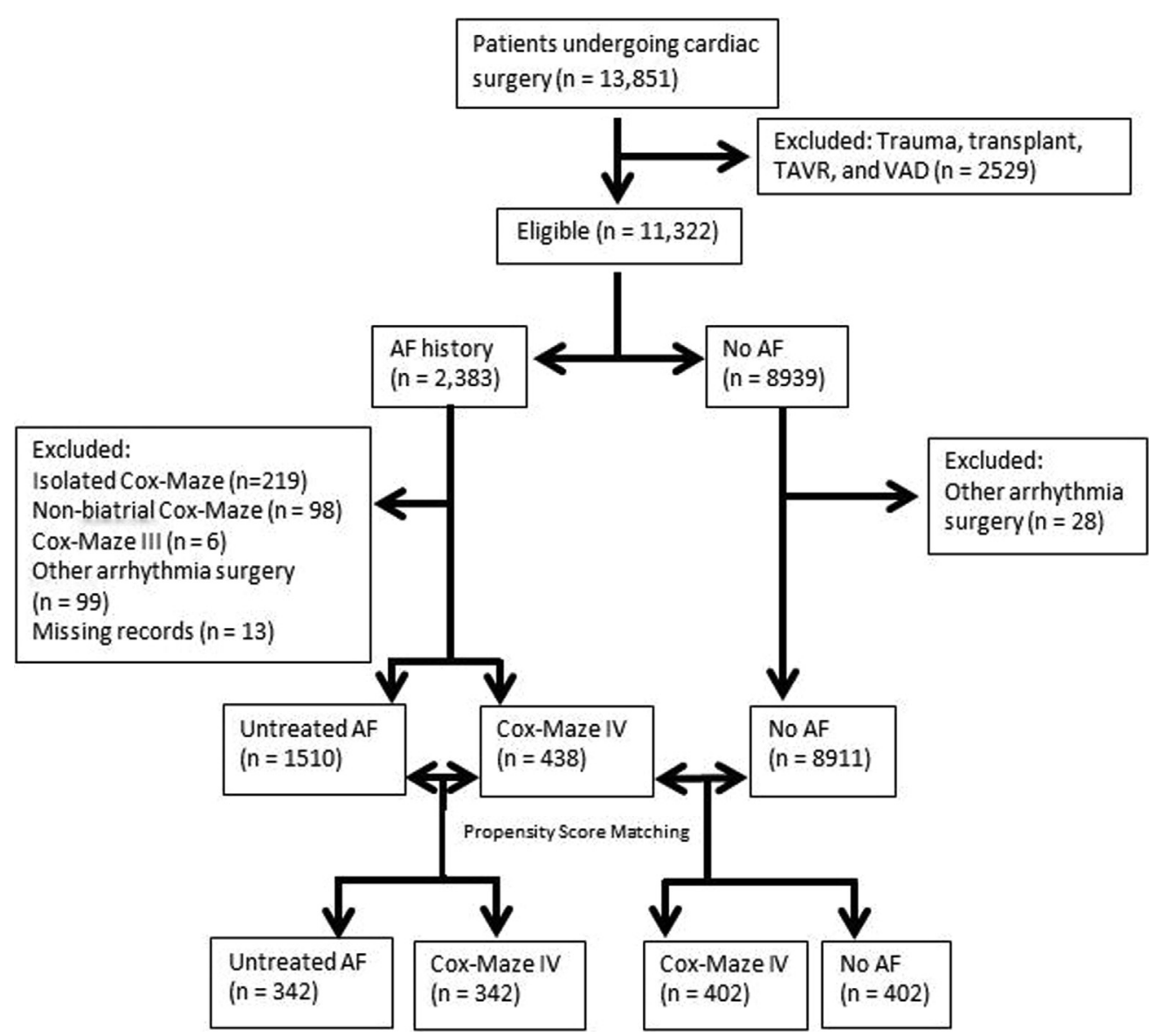

FIGURE 1. Consolidated Standards of Reporting Trials diagram. TAVR, Transcatheter aortic valve replacement; $V A D$, ventricular assist device; $A F$, atrial fibrillation.

(402 pairs) for the CM4 versus No AF groups. Perioperative data were compared between the matched groups.

Kaplan-Meier analysis and log-rank methodology stratified by matched pairs was used to compare the late survival between the matched groups. Survival was measured as time (days) to death based on our electronic medical records or the Social Security Death Index, or time to last follow-up from the date of surgery based only on our electronic medical records. Adjusted hazard ratios were calculated with a Cox proportional hazards regression model stratified by matched pairs that also includes all the covariates used in the propensity model as well as the propensity score, as per the recent recommendations of the Journal of Thoracic and Cardiovascular Surgery. ${ }^{21}$ Proportional hazards assumption was checked quantitatively by adding a time-dependent covariate to a Cox regression model and confirming a nonsignificant $(P>.05)$ effect of the treatment variable (CM4) on the hazard ratio over time for both matched survival comparisons. In addition, we compared the survival between the $342 \mathrm{Un}$ treated AF patients and the $402 \mathrm{No} \mathrm{AF}$ patients who were both previously matched to CM4 using Kaplan-Meier analysis and log-rank methodology. An adjusted hazard ratio was calculated for this comparison as well.

Mean follow-up time between the matched CM4 and Untreated AF groups was $4.2 \pm 3.4$ years and $3.8 \pm 3.8$ years, respectively, and the completeness of follow-up at 10 years was $80 \%$ and $74 \%$, respectively. Between the matched CM4 and No AF groups, the mean follow-up time was $4.0 \pm 3.4$ years and $3.9 \pm 3.8$ years, respectively, and the completeness of follow-up was $75 \%$ and $63 \%$, respectively.
Furthermore, an analysis of the original CM4 patients was performed to determine predictors of mortality using a multivariate Cox proportional hazards regression that included important preoperative variables used for earlier comparisons in addition to left atrial size and type of preoperative AF. A Kaplan-Meier curve was plotted showing the survival of the CM4 patients stratified by type of preoperative AF (paroxysmal vs nonparoxysmal). The hazard ratio obtained for this comparison was obtained from the final model, which included the significant variables from the multivariate regression.

\section{RESULTS}

\section{Preoperative and Perioperative Characteristics}

In the original, unmatched groups, Untreated AF patients had worse comorbidities compared with the CM4 patients (Table 1). The Untreated AF cohort was older, had a lower ejection fraction, lower percentage of females, greater creatinine levels, and a greater proportion of patients with NYHA III/IV symptoms, diabetes, dyslipidemia, history of renal failure, history of dialysis, hypertension, history of cerebrovascular accident, history of myocardial infarction, chronic lung disease, peripheral vascular disease, previous infective endocarditis, previous cardiac surgery, and coronary artery disease. Untreated AF patients 
TABLE 1. Preoperative characteristics of the original, nonmatched groups

\begin{tabular}{|c|c|c|c|}
\hline Variable & Untreated AF $(n=1510)$ & CM4 $(n=438)$ & No $A F(n=8911)$ \\
\hline Age, $y$ & $69 \pm 13 *$ & $66 \pm 11$ & $61 \pm 15^{*}$ \\
\hline Female sex & $621(41 \%)^{*}$ & $199(45 \%)$ & $3324(37 \%)^{*}$ \\
\hline BMI & $29 \pm 7$ & $29 \pm 7$ & $29 \pm 9$ \\
\hline NYHA class III or IV & $1019(68 \%)^{*}$ & $279(64 \%)$ & $4174(47 \%)^{*}$ \\
\hline Ejection fraction & $48.7 \pm 15.4^{*}$ & $54.7 \pm 12.1$ & $52.0 \pm 14.1 *$ \\
\hline Diabetes & $495(33 \%)^{*}$ & $91(21 \%)$ & $2823(32 \%)^{*}$ \\
\hline Dyslipidemia & $1053(70 \%)^{*}$ & $264(60 \%)$ & $6216(70 \%)^{*}$ \\
\hline Last creatinine level & $1.37 \pm 1.00^{*}$ & $1.04 \pm 0.49$ & $1.27 \pm 1.24^{*}$ \\
\hline Renal failure & $229(15 \%)^{*}$ & $18(4 \%)$ & $807(9 \%)^{*}$ \\
\hline Dialysis & $86(6 \%)^{*}$ & $5(1 \%)$ & $368(4 \%)^{*}$ \\
\hline Hypertension & $1177(78 \%)^{*}$ & $313(72 \%)$ & $6600(74 \%)$ \\
\hline Previous CVA & $206(14 \%)^{*}$ & $41(9 \%)$ & $842(9 \%)$ \\
\hline Previous myocardial infarction & $521(35 \%)^{*}$ & $59(14 \%)$ & $3104(35 \%)^{*}$ \\
\hline Chronic lung disease & $513(34 \%)^{*}$ & $99(23 \%)$ & $1772(20 \%)$ \\
\hline Peripheral vascular disease & $357(24 \%)^{*}$ & $357(14 \%)$ & $1760(20 \%)^{*}$ \\
\hline Previous infective endocarditis & $133(9 \%)^{*}$ & $8(2 \%)$ & $553(6 \%)^{*}$ \\
\hline Coronary artery disease & $833(55 \%)^{*}$ & $158(36 \%)$ & $5236(59 \%)^{*}$ \\
\hline Previous cardiac surgery & $499(33 \%)^{*}$ & $42(10 \%)$ & $1487(17 \%)^{*}$ \\
\hline Elective status & $1212(80 \%)^{*}$ & $421(96 \%)$ & $7155(80 \%)^{*}$ \\
\hline \multicolumn{4}{|l|}{ Current surgery } \\
\hline CABG & $571(38 \%)^{*}$ & $119(27 \%)$ & $4636(52 \%)^{*}$ \\
\hline Aortic valve & $566(38 \%)^{*}$ & $94(22 \%)$ & $2520(28 \%)^{*}$ \\
\hline Mitral valve & $509(34 \%)^{*}$ & $279(64 \%)$ & $1557(17 \%)^{*}$ \\
\hline Tricuspid valve & $139(9 \%)$ & $49(11 \%)$ & $231(3 \%)^{*}$ \\
\hline EuroSCORE II (\%) & $7.3 \pm 7.2 *$ & $4.7 \pm 4.0$ & $3.9 \pm 5.1^{*}$ \\
\hline Ambler Score & $10.8 \pm 3.7^{*}$ & $7.9 \pm 2.8$ & $8.0 \pm 4.2$ \\
\hline
\end{tabular}

Values are n (\%) or mean \pm SD. $A F$, Atrial fibrillation; $C M 4$, Cox-maze IV procedure; $B M I$, body mass index; $N Y H A$, New York Heart Association; $C V A$, cerebrovascular accident; $C A B G$, coronary artery bypass grafting; EuroSCORE, European System for Cardiac Operative Risk Evaluation. *Significantly different from CM4.

had a greater percentage of CABG and aortic valve surgeries but a lower fraction of mitral valve surgeries and surgeries classified as elective, compared with CM4 patients. The greater preoperative risk of Untreated $\mathrm{AF}$ patients was represented with a greater EuroSCORE II of $7.3 \pm 7.2$ compared with the $4.7 \pm 4.0$ of the CM4 group and a greater Ambler score of $10.8 \pm 3.7$ versus $7.9 \pm 2.8$.

After propensity matching, the 342 pairs of patients in the Untreated AF and CM4 groups were similar in all patient characteristics (Table 2). The Ambler scores were similar between the groups; however, the CM4 group had a slightly greater EuroSCORE II because the Cox-maze IV procedure is assigned extra risk points in the EuroSCORE II model. Perioperatively, CM4 had a longer cardiopulmonary bypass time (193 \pm 43 minutes vs $132 \pm 153$ minutes, $P<.001)$, crossclamp time $(97 \pm 29$ minutes vs $87 \pm 38$ minutes, $P<.001)$, median intensive care unit length of stay (3.6 days vs 2.2 days, $P \leq .001$ ), and median hospital length of stay ( 11 days vs 8 days, $P<.001$ ). Complications such as reoperation for bleeding, permanent stroke, mediastinitis, renal failure requiring dialysis, and need for intra-aortic balloon pump were similar between the 2 groups. CM4 had a greater rate of pacemaker implantations compared with Untreated AF $(12 \%$ vs $5 \%, P=.002)$ and a slightly greater rate of pneumonia $(11 \%$ vs $7 \%, P=.045)$. Rates of readmission within 30 days were similar between the groups, as was 30-day mortality (Table 2). The unmatched patients of the Untreated AF cohort were not significantly different in any of the preoperative variables from the original Untreated AF cohort.

In the original, unmatched groups, No AF patients also were significantly different from the CM4 patients (Table 1). Despite being younger and having a lower percentage of females and patients with NYHA III/IV symptoms, the No AF cohort was worse than CM4 in most other comorbidities. No AF patients had a lower ejection fraction, 
TABLE 2. Characteristics of the matched CM4 and untreated AF patients

\begin{tabular}{|c|c|c|c|}
\hline Variable & CM4 $(n=342)$ & Untreated AF $(n=342)$ & SMD $(\%)$ \\
\hline Age, $y$ & $68 \pm 11$ & $68 \pm 14$ & 4.85 \\
\hline Female sex & $150(44 \%)$ & $156(46 \%)$ & 3.42 \\
\hline BMI & $29 \pm 7$ & $28 \pm 7$ & 9.01 \\
\hline NYHA class III or IV & $214(63 \%)$ & $209(61 \%)$ & 3.09 \\
\hline Ejection fraction & $53 \pm 12$ & $53 \pm 14$ & 0.76 \\
\hline Diabetes & $83(24 \%)$ & $81(24 \%)$ & 1.40 \\
\hline Dyslipidemia & $213(62 \%)$ & $214(63 \%)$ & 0.62 \\
\hline Last creatinine level & $1.06 \pm 0.54$ & $1.08 \pm 0.48$ & 3.72 \\
\hline Renal failure & $16(5 \%)$ & $14(4 \%)$ & 2.93 \\
\hline Dialysis & $3(1 \%)$ & $3(1 \%)$ & 0.00 \\
\hline Hypertension & $247(72 \%)$ & $251(73 \%)$ & 2.70 \\
\hline Previous CVA & $36(11 \%)$ & $32(9 \%)$ & 3.68 \\
\hline Previous myocardial infarction & $56(16 \%)$ & $61(18 \%)$ & 3.72 \\
\hline Chronic lung disease & $81(24 \%)$ & $70(21 \%)$ & 7.72 \\
\hline Peripheral vascular disease & $50(15 \%)$ & $42(12 \%)$ & 6.74 \\
\hline Previous infective endocarditis & $8(2 \%)$ & $9(3 \%)$ & 1.94 \\
\hline Coronary artery disease & $142(42 \%)$ & $142(42 \%)$ & 0.00 \\
\hline Previous cardiac surgery & $42(12 \%)$ & $41(12 \%)$ & 0.92 \\
\hline Elective status & $327(96 \%)$ & $326(95 \%)$ & 1.44 \\
\hline \multicolumn{4}{|l|}{ Current surgery } \\
\hline CABG & $111(33 \%)$ & $111(33 \%)$ & 0.00 \\
\hline Aortic valve & $90(26 \%)$ & $97(28 \%)$ & 4.71 \\
\hline Mitral valve & $191(56 \%)$ & $189(55 \%)$ & 1.01 \\
\hline Tricuspid valve & $39(11 \%)$ & $40(12 \%)$ & 0.94 \\
\hline EuroSCORE II (\%) & $5.2 \pm 4.4$ & $4.3 \pm 4.6$ & 20.8 \\
\hline Ambler score & $8.2 \pm 2.7$ & $8.5 \pm 3.0$ & 10.5 \\
\hline Perioperative characteristics & & & $P$ value \\
\hline Cardiopulmonary bypass time, $\min$ & $193 \pm 43$ & $132 \pm 53$ & $<.001$ \\
\hline Crossclamp time, $\min$ & $97 \pm 29$ & $87 \pm 38$ & $<.001$ \\
\hline Pacemaker implantation & $41(12 \%)$ & $18(5 \%)$ & .002 \\
\hline Overall major complications & $72(21 \%)$ & $52(16 \%)$ & .093 \\
\hline Reoperation for bleeding & $18(5 \%)$ & $15(4 \%)$ & .722 \\
\hline Permanent stroke & $7(2 \%)$ & $6(2 \%)$ & 1.000 \\
\hline Pneumonia & $39(11 \%)$ & $23(7 \%)$ & .045 \\
\hline Intra-aortic balloon pump & $14(4 \%)$ & $25(7 \%)$ & .106 \\
\hline Mediastinitis & $2(1 \%)$ & $0(0 \%)$ & .499 \\
\hline Renal failure requiring dialysis & $17(5 \%)$ & $11(3 \%)$ & .335 \\
\hline Readmission within $30 \mathrm{~d}$ & $57(17 \%)$ & $54(16 \%)$ & .836 \\
\hline Median ICU LOS, d (IQR range) & $3.6(2.0-6.1)$ & $2.2(1.2-4.1)$ & $<.001$ \\
\hline Median hospital LOS, d (IQR range) & $11(8-15)$ & $8(6-11)$ & $<.001$ \\
\hline 30-d mortality & $10(3 \%)$ & $14(4 \%)$ & .534 \\
\hline
\end{tabular}

Values are $\mathrm{n}(\%)$ or mean $\pm \mathrm{SD}$. Bold indicates statistically significant difference $(P<.05)$. CM4, Cox-maze IV procedure; $A F$, atrial fibrillation; $S M D$, standardized mean difference; $B M I$, body mass index; NYHA, New York Heart Association; $C V A$, cerebrovascular accident; $C A B G$, coronary artery bypass grafting; EuroSCORE, European System for Cardiac Operative Risk Evaluation; $I C U$, intensive care unit; $L O S$, length of stay; $I Q R$, interquartile range. 
TABLE 3. Characteristics of the matched CM4 and no AF patient groups

\begin{tabular}{|c|c|c|c|}
\hline Variable & $\begin{array}{c}\text { CM4 } \\
(n=402)\end{array}$ & $\begin{array}{c}\text { No AF } \\
(n=402)\end{array}$ & $\begin{array}{l}\text { SMD } \\
(\%)\end{array}$ \\
\hline Age, y & $66 \pm 11$ & $66 \pm 12$ & 3.39 \\
\hline Female sex & $173(43 \%)$ & $164(41 \%)$ & 4.46 \\
\hline BMI & $29 \pm 7$ & $30 \pm 18$ & 3.44 \\
\hline NYHA class III or IV & $249(62 \%)$ & $247(61 \%)$ & 1.03 \\
\hline Ejection fraction & $55 \pm 12$ & $54 \pm 13$ & 6.24 \\
\hline Diabetes & $86(21 \%)$ & $74(18 \%)$ & 7.52 \\
\hline Dyslipidemia & $241(60 \%)$ & $252(63 \%)$ & 5.54 \\
\hline Last creatinine level & $1.05 \pm 0.25$ & $1.05 \pm 0.37$ & 0.53 \\
\hline Renal failure & $16(4 \%)$ & $13(3 \%)$ & 4.30 \\
\hline Dialysis & $4(1 \%)$ & $3(1 \%)$ & 3.27 \\
\hline Hypertension & $283(70 \%)$ & $275(68 \%)$ & 4.34 \\
\hline Previous CVA & $39(10 \%)$ & $35(9 \%)$ & 3.46 \\
\hline Previous myocardial infarction & $57(14 \%)$ & $63(16 \%)$ & 4.21 \\
\hline Chronic lung disease & $89(22 \%)$ & $90(22 \%)$ & 0.72 \\
\hline Peripheral vascular disease & $55(14 \%)$ & $57(14 \%)$ & 1.44 \\
\hline Previous infective endocarditis & $8(2 \%)$ & $7(1.7 \%)$ & 2.23 \\
\hline Coronary artery disease & $152(38 \%)$ & $160(40 \%)$ & 4.11 \\
\hline Previous cardiac surgery & $42(10 \%)$ & $41(10 \%)$ & 0.66 \\
\hline Elective status & $387(96 \%)$ & $384(96 \%)$ & 4.04 \\
\hline \multicolumn{4}{|l|}{ Current surgery } \\
\hline CABG & $115(29 \%)$ & $120(30 \%)$ & 2.86 \\
\hline Aortic valve & $93(23 \%)$ & $92(23 \%)$ & 0.48 \\
\hline Mitral valve & $249(62 \%)$ & $254(63 \%)$ & 2.69 \\
\hline Tricuspid valve & $28(7 \%)$ & $33(8 \%)$ & 4.53 \\
\hline EuroSCORE II ( \%) & $4.7 \pm 4.1$ & $3.7 \pm 4.4$ & 21.7 \\
\hline Ambler score & $7.7 \pm 7.7$ & $6.7 \pm 3.1$ & 17.0 \\
\hline Perioperative characteristics & & & $P$ value \\
\hline Cardiopulmonary bypass time, min & $193 \pm 43$ & $130 \pm 46$ & $<.001$ \\
\hline Crossclamp time, min & $98 \pm 28$ & $86 \pm 32$ & $<.001$ \\
\hline Pacemaker implantation & $43(11 \%)$ & $27(7 \%)$ & .060 \\
\hline \multicolumn{4}{|l|}{ Overall major complications } \\
\hline Reoperation for bleeding & $22(6 \%)$ & $14(4 \%)$ & .232 \\
\hline Permanent stroke & $6(2 \%)$ & $8(2 \%)$ & .789 \\
\hline Pneumonia & $42(10 \%)$ & $25(6 \%)$ & .041 \\
\hline Intra-aortic balloon pump & $15(4 \%)$ & $25(6 \%)$ & .144 \\
\hline Mediastinitis & $2(1 \%)$ & $0(0 \%)$ & .499 \\
\hline Renal failure requiring dialysis & $20(5 \%)$ & $12(3 \%)$ & .206 \\
\hline Readmission within $30 \mathrm{~d}$ & $68(17 \%)$ & $41(10 \%)$ & .007 \\
\hline Median ICU LOS, d (IQR range) & $3.2(1.9-6.0)$ & $2.0(1.0-4.0)$ & $<.001$ \\
\hline Median Hospital LOS, d (IQR range) & $10(7-14)$ & $7(5-10)$ & $<.001$ \\
\hline 30-d mortality & $12(3 \%)$ & $12(3 \%)$ & 1.000 \\
\hline
\end{tabular}

Values are $\mathrm{n}(\%)$ or mean \pm SD. Bold indicates statistically significant difference $(P<.05) . C M 4$, Cox-maze IV procedure; $A F$, atrial fibrillation; $S M D$, standardized mean difference; $B M I$, body mass index; $N Y H A$, New York Heart Association; $C V A$, cerebrovascular accident; $C A B G$, coronary artery bypass grafting; EuroSCORE, European System for Cardiac Operative Risk Evaluation; ICU, intensive care unit; $L O S$, length of stay; $I Q R$, interquartile range. 


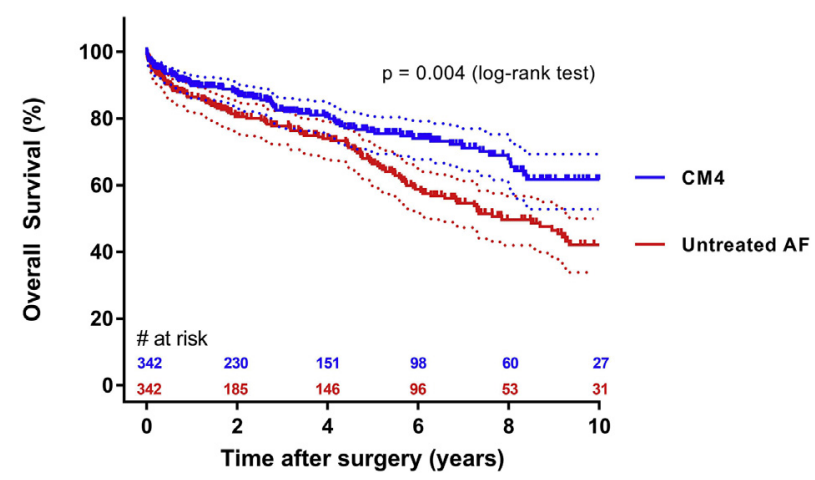

FIGURE 2. Kaplan-Meier curve showing the survival of the matched CM4 and Untreated AF groups. CM4, Cox-maze IV procedure; $A F$, atrial fibrillation.

a greater last creatinine level, and a greater proportion of patients with diabetes, dyslipidemia, history of renal failure, history of dialysis, history of myocardial infarction, peripheral vascular disease, previous infective endocarditis, previous cardiac surgery, and coronary artery disease. No AF patients also had a greater fraction of $\mathrm{CABG}$ and aortic valve surgeries, a lower fraction of mitral valve surgeries, tricuspid valve surgeries, and surgeries classified as elective, compared with the CM4 patients. The preoperative risk of No AF patients compared with the CM4 patients is represented with a EuroSCORE II of $3.9 \pm 5.1$ versus $4.7 \pm 4.0$, respectively, and an Ambler score of $8.0 \pm 4.2$ versus $7.9 \pm 2.8$, respectively.

After matching, the 402 pairs of patients in the No AF and CM4 groups were similar in all patient characteristics (Table 3). The CM4 group had a slightly greater Ambler score and EuroSCORE II because the Ambler score assigns 1 risk point to $\mathrm{AF}$ as a demographic variable, and the EuroSCORE II assigns extra risk points to the Cox-maze IV procedure. Perioperatively, CM4 had a longer cardiopulmonary bypass time (193 \pm 43 minutes vs $130 \pm 46$ minutes, $P<.001$ ), crossclamp time (98 \pm 28 minutes vs $86 \pm 32$ minutes, $P<.001$ ), median intensive care unit length of stay ( 3.2 days vs 2.0 days, $P \leq .001$ ), and median hospital length of stay (10 days vs 7 days, $P<.001)$. Complications such as reoperation for bleeding, permanent stroke, mediastinitis, renal failure requiring dialysis, pacemaker implantation, and need for intra-aortic balloon pump were similar between the 2 groups, except for a slightly greater rate of pneumonia in CM4 (10\% vs $6 \%, P=.041)$. Rates of readmission within 30 days were lower in the No AF group compared with CM4 (10\% vs $17 \%$, $P=.007)$. Thirty-day mortality was similar between the 2 groups (Table 3).

\section{Survival Outcomes of the Matched Groups}

Kaplan-Meier analysis showed an improved survival for the CM4 patients compared with Untreated AF patients (Figure $2, P=.004$ ). Survival at 10 years was $62 \%$ for

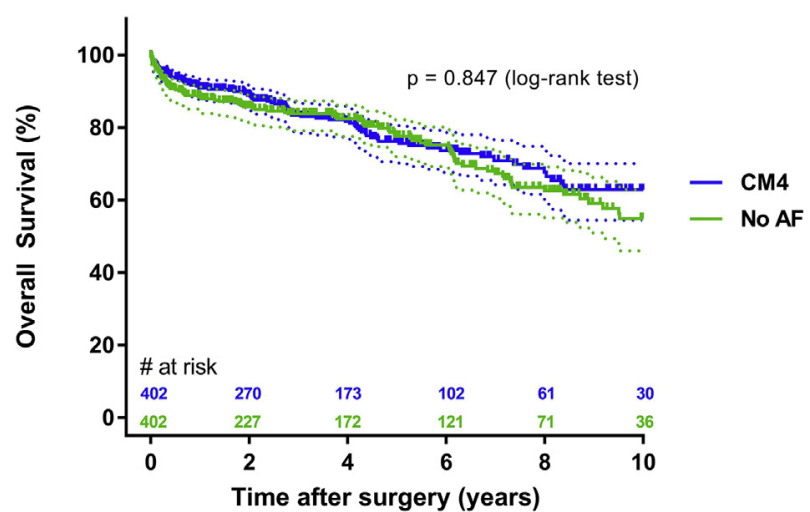

FIGURE 3. Kaplan-Meier curve showing the survival of the matched CM4 and No AF groups. CM4, Cox-maze IV procedure; $A F$, atrial fibrillation.

the CM4 group and $42 \%$ for Untreated $\mathrm{AF}$ group. Adjusted hazard ratio was 0.47 (95\% confidence interval $[\mathrm{CI}], 0.26-0.86, P=.014)$. When we compared the matched CM4 and No AF groups, no difference in the overall survival was found between the groups with Kaplan-Meier analysis (Figure $3, P=.847$ ). Survival at 10 years was $63 \%$ for the CM4 group and 55\% for the No AF group. Adjusted hazard ratio was $1.03(95 \% \mathrm{CI}, 0.51-2.11, P=.929)$.

We also compared the survival of the 342 Untreated AF patients who were matched to CM4 with the 402 No AF patients who were matched to CM4. Untreated AF patients showed worse survival than the No AF patients (Figure 4, $P=.001$ ). Survival at 10 years was $55 \%$ for No AF patients and $42 \%$ for Untreated AF patients. The 2 cohorts were similar in all covariates except for a slightly older age and a lower percentage of mitral valve procedures in the Untreated AF patients. After we adjusted for all covariates using a Cox proportional hazards regression model, preoperative $\mathrm{AF}$ remained an independent predictor of mortality with an adjusted hazard ratio of $1.38(95 \% \mathrm{CI}$, $1.04-1.83, P=.025$ ).

\section{Predictors of Mortality in the CM4 Group}

Multivariate analysis of the original CM4 patient cohort $(n=438)$ identified 4 significant predictors of mortality. These were type of preoperative AF (paroxysmal vs nonparoxysmal; hazard ratio 0.55 [95\% CI, 0.353-0.856, $P=.008]$ ), history of myocardial infarction (hazard ratio 2.37 [95\% CI, 1.44-3.89, $P=.001]$ ), chronic lung disease (hazard ratio 1.97 [95\% CI, 1.27-3.07, $P=.003]$ ), and age (hazard ratio $1.03[95 \% \mathrm{CI}, 1.01-1.06, P=.004]$ ). A Kaplan-Meier curve was used to plot the survival of the CM4 patients stratified by the type of preoperative AF (Figure 5). Survival at 5 years was $86 \%$ for patients with paroxysmal $\mathrm{AF}$ and $72 \%$ for patients with nonparoxysmal AF. Survival at 10 years was $69 \%$ for patients with paroxysmal AF compared with $61 \%$ for patients with nonparoxysmal AF. 


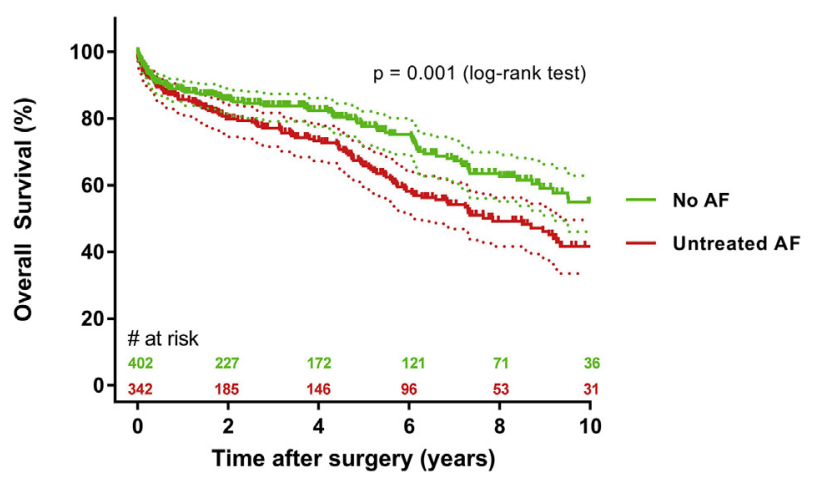

FIGURE 4. Kaplan-Meier curve showing the survival of the Untreated $\mathrm{AF}$ patients and the No AF patients who were previously matched to the CM4 group. AF, Atrial fibrillation.

\section{DISCUSSION}

The primary finding of our study was that the addition of a CM4 for patients undergoing cardiac surgery with a history of AF was associated with improved late survival compared with patients whose AF was left untreated, without a significant increase in postoperative morbidity or mortality in the CM4 group. In addition, patients receiving a concomitant CM4 had a similar survival to a comparable population undergoing cardiac surgery without a history of AF (Video 1).

Several studies have demonstrated that patients with preoperative $\mathrm{AF}$ who undergo cardiac surgery for correction of valve and/or coronary disease have increased morbidity and mortality compared with patients who undergo surgery in normal sinus rhythm. ${ }^{3-7}$ Ngaage and colleagues ${ }^{6}$ demonstrated that for patients undergoing CABG procedures, preoperative $\mathrm{AF}$ was an independent predictor of cardiac death (hazard ratio 2.75, $P=.001$ ) and all-cause mortality (hazard ratio $1.34, P=.05$ ). However, it has not been well established that the restoration of sinus rhythm with a concomitant ablation procedure improves late survival in surgical patients. This would be important in documenting whether AF has a causal relationship, rather than simply an association with poor outcomes. In our study, we demonstrated that when we take a population of patients similar to the ones receiving the CM4 who are undergoing cardiac surgery without a concomitant

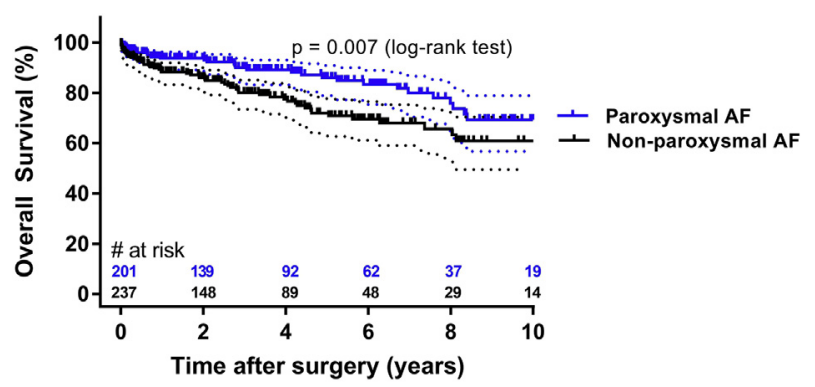

FIGURE 5. Kaplan-Meier curve showing the survival of the CM4 patients stratified by type of preoperative AF. $A F$, Atrial fibrillation. ablation, a history of AF was associated with decreased late survival compared with patients without a history of AF. AF was identified on multivariate analysis as an independent predictor of mortality, with an adjusted hazard ratio of 1.38 (95\% CI, 1.04-1.83, $P=.025)$.

The CM4 has been shown to be the most effective surgical procedure for ablating AF. Our group has previously shown that concomitant CM4 had similar outcomes as a stand-alone CM4, with $93 \%$ and $81 \%$ freedom from $\mathrm{AF}$ at 1 and 5 years, as well as $84 \%$ and $69 \%$ freedom from $\mathrm{AF}$ and $\mathrm{AADs}$ at 1 and 5 years, respectively. ${ }^{13}$ One would hypothesize that because untreated AF is associated with a worse survival after cardiac surgery, then adding an effective surgical ablation procedure might be associated with an improved survival over the years. A few studies have suggested that this might be the case. Ad and colleagues ${ }^{10}$ have shown that for patients undergoing mitral valve or mitral + tricuspid valve surgery with a history of AF, undergoing a concomitant Cox-maze procedure was associated with similar 4-year survival to a propensity-matched group of patients without a history of AF. In addition, patients with untreated AF had a lower 4-year survival than those receiving a concomitant Cox-maze when a multivariate regression model was used (hazard ratio $2.47, P=.048$ ); however, this comparison was not performed using propensity score matching. McCarthy and colleagues ${ }^{11}$ have also shown that patients with paroxysmal AF that was left untreated at the time of cardiac surgery had worse 5-year survival in a propensity-matched comparison with patients who received concomitant AF ablation at the time of surgery (hazard ratio $0.47, P=.007)$. In addition, patients with paroxysmal $\mathrm{AF}$ who received concomitant AF ablation had a similar 5 -year survival to a propensity-matched group of patients who underwent surgery without a history of AF. However, when the patients whose paroxysmal AF was left untreated were compared with patients without a history of AF, the hazard ratio failed to remain significant after adjustment (hazard ratio $1.47, P=.099$ ).

Our study demonstrated similar results for survival in the long term. Patients with a history of AF undergoing cardiac surgery are a very heterogeneous group. Those who did not receive a concomitant CM4 had much worse comorbidities than those who received a CM4. The decision not to perform an ablation was usually made when the risks seemed to outweigh the benefits especially in very ill and frail patients, in combination with the complexity of the procedure in hand. It is difficult to place cut-offs or rigid rules on when a concomitant CM4 should not be performed. We calculated and reported the EuroSCORE II and Ambler score to provide an idea about the risk profiles of the patient groups. Patients whose AF was left untreated had greater risk scores compared with those receiving a concomitant CM4. 


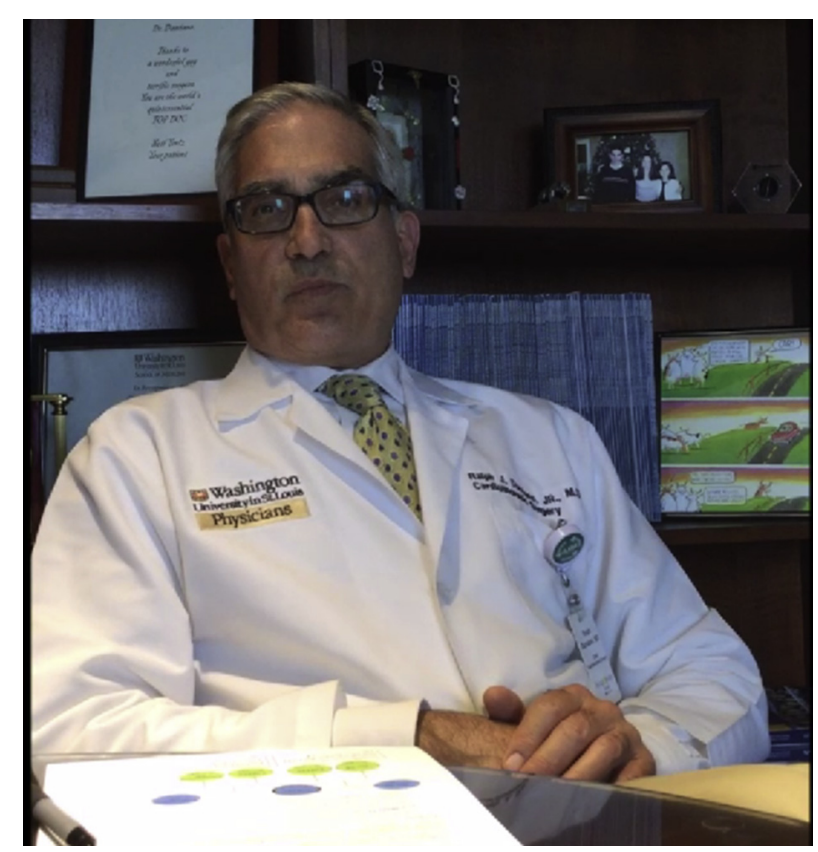

VIDEO 1. Ralph J. Damiano, Jr, MD, summarizes the study and explains the relevance of the research in the context of the literature. Video available at: http://www.jtcvsonline.org/article/S0022-5223(17)32137-2/fulltext.

Despite these differences, our large sample sizes allowed us to perform an excellent propensity match that resulted in 2 groups that were similar in all measured covariates. Our results showed that in this selected population, patients receiving a concomitant CM4 had a significantly better late survival than those whose AF was left untreated. In addition, with our reported high freedom from AF experience in the CM4 patients, we tested the hypothesis that patients who underwent concomitant CM4 would be expected to have a similar survival to patients undergoing cardiac surgery without a history of AF. After propensity matching these groups, we demonstrated that this was indeed the case, with a hazard ratio of $1.03(95 \% \mathrm{CI}$, $0.51-2.11, P=.929)$. For the sake of completion and increased validity of our study, we performed a comparison between the patients with untreated AF who were matched to CM4 patients, and patients without an AF history who were matched to CM4, to check if AF history would be associated with decreased survival in this selected patient population. Multivariate analysis using a Cox-proportional hazards model did identify AF as a predictor of mortality with a hazard ratio of $1.38(95 \%$ CI, 1.04-1.83, $P=.025)$. These data support our hypothesis that for selected patients who are undergoing cardiac surgery, a history of AF is associated with worse survival, and that adding the CM4 improves survival for these patients and provides a survival similar to patients without a history of AF. Our results emphasize the importance of treating AF at the time of surgery in patients in whom the ablation procedure can be performed without significantly adding to perioperative morbidity or mortality.

In addition, multivariate analysis of patients with a history of AF undergoing concomitant CM4 identified the type of AF, previous myocardial infarction, chronic lung disease, and age as significant predictors of mortality. The hazard ratio associated with the type of AF (paroxysmal vs nonparoxysmal) was significant at 0.55 (95\% CI, $0.353-0.856, P=.008$ ). The better survival of patients with paroxysmal AF provides a rationale for earlier referral of patients for surgical ablation before substrate remodeling results in long-standing persistent $\mathrm{AF}$.

\section{Limitations}

This study had several limitations. First, this was a retrospective case series, which introduces inherent potential biases that could have been avoided if this study had been performed in a prospective fashion. However, most of the data were collected concurrently and entered into our STS database, and this was a series of consecutive patients. Regular rhythm follow-up and data regarding late adverse events like stroke/bleeds were only available for CM4 and not the Untreated AF or No AF patients. This is due to the presence of a dedicated institutional database for patients who undergo a Cox-maze procedure in which patients are followed at regular intervals and their rhythm data collected concurrently. Therefore, we were not able to determine the influence of rhythm status on late adverse events or survival between the groups. In addition, we used all-cause mortality in our analysis because the specific cause of death was not available in most cases.

Another limitation is that the patients who were selected to receive the CM4 were "healthier" originally than the Untreated AF patients. Even though our match used 22 variables and the matched groups were similar in all covariates, some unmeasured variables and the "eyeball test of patient frailty" might still account for some of the survival advantage in the CM4 patients. However, when we compared the 402 No AF patients with the 342 Untreated AF patients, Untreated AF patients still showed worse survival compared with No AF patients, although they were similar in most comorbidities. Multivariate analysis confirmed the independent influence of AF history on survival. Finally, our knowledge of AF history, such as duration of AF, was limited in the Untreated AF patients compared with the CM4 patients. When comparing the type of $\mathrm{AF}, 62 \%$ of the Untreated $\mathrm{AF}$ had paroxysmal $\mathrm{AF}$ and $38 \%$ had nonparoxysmal, whereas for the CM4 patients, $45 \%$ had paroxysmal and $55 \%$ had nonparoxysmal AF. This implies that even though the CM4 had a greater burden of AF, they still performed better in terms of long-term survival than patients whose AF was 
left untreated, further underscoring the importance of treating AF at the time of surgery.

\section{CONCLUSIONS}

Our study suggested that for selected patients with a history of AF undergoing cardiac surgery, concomitant CM4 did not add significantly to postoperative morbidity or mortality and was associated with improved late survival compared with patients whose AF was left untreated during the time of surgery. Moreover, in patients who underwent a CM4, there was similar survival to patients who underwent cardiac surgery without a history of AF. Our results should encourage surgeons to treat AF at the time of surgery in appropriate patients.

\section{Webcast}

You can watch a Webcast of this AATS meeting presentation by going to: https://aats.blob.core.windows. net/media/17AM/2017-05-03/RM302-304/05-03-17_Room 302-304_0854_Musharbash.mp4.

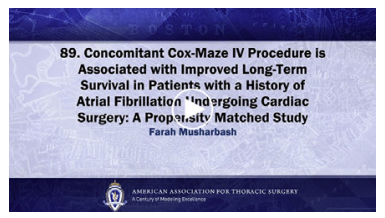

\section{Conflict of Interest Statement}

Dr Damiano, Jr, is a consultant for and receives research funding from AtriCure. He has received speakers' fees from LivaNova. All other authors have nothing to disclose with regard to commercial support.

The authors acknowledge administrative support provided by Jennifer Bell, RN, BSN, CCRC.

\section{References}

1. Benjamin EJ, Wolf PA, D'Agostino RB, Silbershatz H, Kannel WB, Levy D Impact of atrial fibrillation on the risk of death: the Framingham Heart Study. Circulation. 1998;98:946-52.

2. Stewart S, Hart CL, Hole DJ, McMurray JJ. A population-based study of the long-term risks associated with atrial fibrillation: 20-year follow-up of the Renfrew/Paisley study. Am J Med. 2002;113:359-64.

3. Ngaage DL, Schaff HV, Mullany CJ, Barnes S, Dearani JA, Daly RC, et al. Influence of preoperative atrial fibrillation on late results of mitral repair: is concomitant ablation justified? Ann Thorac Surg. 2007;84:434-42; discussion 442-3.

4. Ngaage DL, Schaff HV, Barnes SA, Sundt TM III, Mullany CJ, Dearani JA, et al. Prognostic implications of preoperative atrial fibrillation in patients undergoing aortic valve replacement: is there an argument for concomitant arrhythmia surgery? Ann Thorac Surg. 2006;82:1392-9.

5. Schulenberg R, Antonitsis P, Stroebel A, Westaby S. Chronic atrial fibrillation is associated with reduced survival after aortic and double valve replacement. Ann Thorac Surg. 2010;89:738-44.

6. Ngaage DL, Schaff HV, Mullany CJ, Sundt TM III, Dearani JA, Barnes S, et al. Does preoperative atrial fibrillation influence early and late outcomes of coronary artery bypass grafting? J Thorac Cardiovasc Surg. 2007;133:182-9.

7. Wang B, Xu ZY, Han L, Zhang GX, Lu FL, Song ZG. Impact of preoperative atrial fibrillation on mortality and cardiovascular outcomes of mechanical mitral valve replacement for rheumatic mitral valve disease. Eur J Cardiothorac Surg. 2013;43:513-9.

8. Lee R, McCarthy PM, Wang EC, Vaduganathan M, Kruse J, Malaisrie SC, et al. Midterm survival in patients treated for atrial fibrillation: a propensity-matched comparison to patients without a history of atrial fibrillation. J Thorac Cardiovasc Surg. 2012;143:1341-51; discussion 1350-1.

9. Attaran S, Saleh HZ, Shaw M, Ward A, Pullan M, Fabri BM. Does the outcome improve after radiofrequency ablation for atrial fibrillation in patients undergoing cardiac surgery? A propensity-matched comparison. Eur J Cardiothorac Surg. 2012;41:806-10; discussion 810-1.

10. Ad N, Holmes SD, Massimiano PS, Pritchard G, Stone LE, Henry L. The effect of the Cox-maze procedure for atrial fibrillation concomitant to mitral and tricuspid valve surgery. J Thorac Cardiovasc Surg. 2013;146:1426-34; discussion 1434-5.

11. McCarthy PM, Manjunath A, Kruse J, Andrei AC, Li Z, McGee EC Jr, et al. Should paroxysmal atrial fibrillation be treated during cardiac surgery? J Thorac Cardiovasc Surg. 2013;146:810-3.

12. Cox JL, Schuessler RB, D'Agostino HJ Jr, Stone CM, Chang BC, Cain ME, et al. The surgical treatment of atrial fibrillation. III. Development of a definitive surgical procedure. J Thorac Cardiovasc Surg. 1991;101: 569-83.

13. Henn MC, Lancaster TS, Miller JR, Sinn LA, Schuessler RB, Moon MR, et al. Late outcomes after the Cox maze IV procedure for atrial fibrillation. J Thorac Cardiovasc Surg. 2015;150:1168-76. 1178.e1-2.

14. Ad N, Henry L, Hunt S, Holmes SD. Do we increase the operative risk by adding the Cox Maze III procedure to aortic valve replacement and coronary artery bypass surgery? J Thorac Cardiovasc Surg. 2012;143:936-44.

15. Saint LL, Damiano RJ Jr, Cuculich PS, Guthrie TJ, Moon MR, Munfakh NA, et al. Incremental risk of the Cox-maze IV procedure for patients with atrial fibrillation undergoing mitral valve surgery. J Thorac Cardiovasc Surg. 2013; 146:1072-7.

16. Lawrance CP, Henn MC, Damiano RJ Jr. Concomitant Cox-Maze IV techniques during mitral valve surgery. Ann Cardiothorac Surg. 2015;4:483-6.

17. Robertson JO, Lawrance CP, Maniar HS, Damiano RJ Jr. Surgical techniques used for the treatment of atrial fibrillation. Circ J. 2013;77:1941-51.

18. Robertson JO, Saint LL, Leidenfrost JE, Damiano RJ Jr. Illustrated techniques for performing the Cox-Maze IV procedure through a right mini-thoracotomy. Ann Cardiothorac Surg. 2014;3:105-16.

19. Saint LL, Lawrance CP, Leidenfrost JE, Robertson JO, Damiano RJ Jr. How I do it: minimally invasive Cox-Maze IV procedure. Ann Cardiothorac Surg. 2014;3: $117-9$.

20. Calkins H, Kuck KH, Cappato R, Brugada J, Camm AJ, Chen SA, et al. 2012 HRS/EHRA/ECAS Expert Consensus Statement on Catheter and Surgical Ablation of Atrial Fibrillation: recommendations for patient selection, procedural techniques, patient management and follow-up, definitions, endpoints, and research trial design. Europace. 2012;14:528-606.

21. McMurry TL, Hu Y, Blackstone EH, Kozower BD. Propensity scores: methods, considerations, and applications in the Journal of Thoracic and Cardiovascular Surgery. J Thorac Cardiovasc Surg. 2015;150:14-9.

Key Words: atrial fibrillation, Cox-maze IV, survival

\section{Discussion}

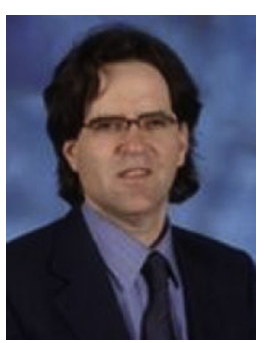

Dr N. Ad (Falls Church, Va). First, I would like to thank the American Association for Thoracic Surgery for the privilege of discussing this paper. I want to take a second and recognize that in front of us is a second-year medical student from Wash $\mathrm{U}$ who conducted himself in an exceptionally professional way and impressive way, in sending the paper to me and discussing it and so on and so forth. I was very impressed and thank you for that. 
The paper itself is basically representing the excellent work that is being done in St Louis for many years in the field of surgical ablation for atrial fibrillation. Long-term survival benefit is well documented in large series from big centers, including ours, when it comes to observational studies like that. We have currently a significant gap in the literature with randomized controlled trials, as those are all stopped at approximately 1 year after surgery; that's not enough time to show the differences. You showed very clearly that there is an advantage of performing a maze procedure in patients with atrial fibrillation with all the limitations of propensity matching and so on and so forth.

I have a few questions for you, and I will ask them one after the other. Do you think that part of the effect of what you see today analyzing the data is simply a selection bias on the surgeon level? In our center, I can clearly tell you that the better surgeons, the more experienced ones, are those who are performing the maze procedure as opposed to the other. So, were there any differences in the group that performed or didn't perform surgical ablation?

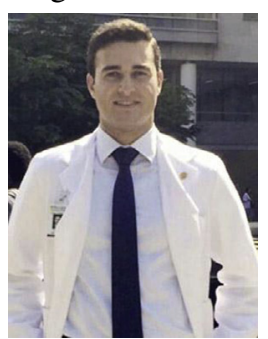

Mr Farah N. Musharbash (St. Louis, $M o$ ). Thank you very much, $\mathrm{Dr} \mathrm{Ad}$, for your kind and generous comments.

The experience of the surgeon is very important and it definitely impacts the outcomes as you had shown yesterday in your plenary talk. When we look at our own study, $83 \%$ of the concomitant mazes were performed by a single surgeon, Dr Damiano, whereas he performed 18\% of the procedures in the Untreated AF group, and so definitely there is a disparity there. If you look at the experience, let's say, from the technical skills aspect, although that is something that we haven't directly accounted for, when we look at our perioperative data, our 30-day mortality was the same between the groups and our major complications were similar and in fact a little bit greater in the maze group. Therefore, we don't suspect that differences in the technical ability of the surgeons accounted for the long-term survival differences.

However, if we look at the experience in another way, which is the experience in selecting the patients, I think that is extremely important; that definitely impacts the long-term survival. In that regard, however, we have accounted for it by including most of the comorbidities as covariates in our propensity match and ending up with a good match at the end.

Dr Ad. The second question is where I have a problem with such studies. We perform surgical ablation to eliminate atrial fibrillation. So when we follow our patients, I think we need to be able to show the effect of the treatment on the outcome. Conversely, when we don't treat patients with atrial fibrillation, some of them are going to be self-converted and be in sinus rhythm.

Do you have any effect of your treatment long term to show that actually the effect of the maze procedure on the rate of atrial fibrillation long term as opposed to the self-conversion long term had any effect rather than just performing the procedure, going back to the surgeon bias that may create all these problems with assessing long-term results?

Mr Musharbash. I think that is an excellent point. In our center we have a database for all the patients who undergo a Cox-maze, and we prospectively collect data on the rhythms and stroke in a way that is consistent with the guidelines. Unfortunately, we don't have that kind of information for patients who do not undergo a Cox-maze, and so all those patients in the Untreated AF group, we don't have that kind of information for them, and that makes it extremely challenging to be able to compare the rhythms between the 2 groups and be able to link that to the survival difference that we have seen.

Now, having said that, even though in this study we haven't really been able to connect all of the dots from the beginning to the end, we definitely relied on knowledge we have seen from the literature from our group and from your group and other groups in that the Cox-maze does provide significant improvement in the rhythms and does restore sinus rhythm in a lot of patients. When we published our 5-year outcomes, we did a subgroup analysis on just the concomitant mazes, and we showed that at 1 year, the freedom from atrial fibrillation was $93 \%$ and it was $81 \%$ at 5 years and the freedom from atrial fibrillation and AAD was $84 \%$ at 1 year and $69 \%$ at 5 years, and that was similar to the patients who had alone or standalone maze procedures.

Dr Ad. The last question is something you didn't present but I think it is important to bring up very quickly. You showed a difference in survival between the paroxysmal and the nonparoxysmal patients. I think this is really important. I was surprised by that.

Do you have data that patients who have other than paroxysmal atrial fibrillation, maybe the type of atrial fibrillation is a marker for a sicker patient that may reflect the long-term results?

Mr Musharbash. Yes. As you mentioned, this is something that we didn't have time to include in the slides and the presentation, but we did take the 438 patients who underwent a Cox-maze and we used multivariate analysis to find predictors of mortality at the end of those 10 years, and we found 4: age, myocardial infarction, chronic lung disease, and interestingly, the type of preoperative atrial fibrillation. I think that is a very interesting point, because previously in our studies we did not find that the type of preoperative atrial fibrillation was a predictor of recurrence and yet here we find it to be a predictor of survival somehow. 
When we looked at those paroxysmal versus the persistent or nonparoxysmal patients and we looked back at them, there were no differences in the comorbidities, but what was different was that a greater percentage of those patients who had persistent atrial fibrillation were undergoing more mitral valve surgery and less of them were undergoing aortic valve surgery. Even though mitral valve surgery itself was not a predictor, it could be that the more significant atrial remodeling was somehow contributing to those outcomes. This is purely speculative, I think.

I go back to your study yesterday where in your conclusions you talked about the importance going forward of trying to look at any changes in the structure of the heart after the patients undergo a Cox-maze and a mitral valve procedure and seeing if that has an effect on the outcome, and I think that might elucidate some of the questions you have today.

Dr Ad. Thank you, and I hope you choose cardiac surgery as your profession. You are very impressive.

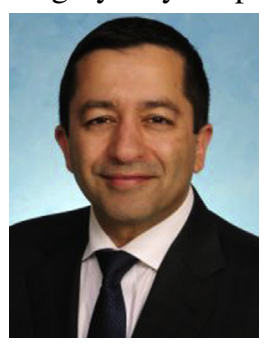

Dr V. Badhwar (Morgantown, WVa). Again, congratulations on your poise at the podium. Congratulations on contributing again to the literature showing that adding a Cox-maze procedure improves survival.

If atrial fibrillation was to recur after a maze, was survival superiority maintained? It is unusual to have a paper that has the data that can answer that question. Did you look at that, and if you have not, could you?

Mr Musharbash. That is an excellent question. Thank you, Dr Badhwar. There was a paper by Dr Lee. He took the maze patients and divided them at 1 year whether they were in atrial fibrillation or no atrial fibrillation, and then he followed up I think for 5 years and looked at the survival; and he did show that patients who were in sinus rhythm at that time, at 1 year, which he called a success, had better survival than the patients who had atrial fibrillation. We did that for our group as something on the side, and the problem with that is in the guidelines the definition of a success was at 1 year whether there was atrial fibrillation or no atrial fibrillation, and our success rate at 1 year was $93 \%$. So we ended up with about 30 or 40 patients who were considered failures. And when we looked at that, there seemed to be a trend; however, we did not find anything significant in terms of that, and I think that would be very interesting to look at later.

But one of the problems, again, is the operation reduces the burden of atrial fibrillation, and when we are looking at a span of 10 years, would we really capture at one appointment or, let's say, 24 hours at 1 year and make a decision whether the whole procedure was a success or a failure. I think that is one of the limitations of trying to do such a comparison.

Readers who found these articles interesting may also like to read the following papers found in recent and future issues of our sister publications, Seminars in Thoracic and Cardiovascular Surgery and Operative Techniques in Thoracic and Cardiovascular Surgery!

Acquired: Arrhythmia

ORIGINAL SUBMISSION: Mid-Term Performance of Bipolar Radiofrequency Ablation for Isolated Atrial Fibrillation Through a Right Minithoracotomy Giuseppe Nasso. Semin Thoracic Surg 2017:160-172.

ORIGINAL SUBMISSION: Predictors of Long-term Success After Concomitant Surgical Ablation for Atrial Fibrillation Simon Pecha. Semin Thoracic Surg 2017: In press.

Editorial Commentary: Longitudinal Studies in Surgical Ablation for Atrial Fibrillation: the Next Step Dawn S. Hui. Semin Thoracic Surg 2017: In press. 